\title{
Population Genetic Structure of Claviceps purpurea in Cool-Season Grass Seed Crops of Oregon
}

\author{
Qunkang Cheng, ${ }^{1}$ Kenneth E. Frost, ${ }^{2}$ and Jeremiah K. S. Dung ${ }^{1, \dagger}$
}

${ }^{1}$ Department of Botany and Plant Pathology, Central Oregon Agricultural Research Center, Oregon State University, Madras, OR

${ }^{2}$ Department of Botany and Plant Pathology, Hermiston Agricultural Research and Extension Center, Oregon State University, Hermiston, OR Accepted for publication 19 June 2020.

ABSTRACT

\begin{abstract}
Ergot, caused by Claviceps purpurea, is a primary disease concern in irrigated cool-season grass seed production systems of Oregon. In order to better understand the genetic diversity, population structure, and the epidemiology of $C$. purpurea in grasses grown for seed, 226 isolates were obtained using a hierarchical sampling strategy from two fields each of Kentucky bluegrass $(n=102)$ and perennial ryegrass $(n=124)$ and characterized using 12 microsatellite markers. A total of 194 unique multilocus genotypes (MLGs) were identified in this study. There were moderate levels of genotypic diversity $(H=3.43$ to 4.23$)$ and gene diversity $\left(H_{\exp }=0.45\right.$ to 0.57$)$ within fields. After clone correction, analysis of molecular variance revealed that $66 \%$ of the genetic variation occurred between the two $C$. purpurea isolates collected from the same seed head of individual plants, indicating that many of the seed heads bearing multiple sclerotia were infected by ascospores rather than
\end{abstract}

conidia. However, the majority of the clonal isolates obtained in this study were collected from the same seed head (i.e., the two isolates were identical MLGs), indicating a role of conidia (honeydew) in secondary infections within seed heads. Genetic differentiation was observed between populations from different hosts $(22 \%)$ but was confounded by geography. The standardized index of association ranged from 0.007 to 0.122 among the four populations, suggesting potential outcrossing and differences in the relative contribution of ascospores and conidia to ergot among the fields. The results from this study provide insights into the epidemiology of ergot in cool-season grass seed crops of Oregon.

Keywords: ecology and epidemiology, ergot, Kentucky bluegrass, mycology, perennial ryegrass, plant disease epidemiology, population genetics
Cool-season grass seed is an important agricultural commodity in the U.S. Pacific Northwest. The state of Oregon, which is the world's leading producer of cool-season grass seed, produced over 23 million pounds of Kentucky bluegrass (Poa pratensis L.) seed and over 321 million pounds of perennial ryegrass (Lolium perenne L.) seed in 2017, which accounted for over 34 and $90 \%$ of total U.S. production that year, respectively (USDA NASS 2017).

Ergot, caused by fungi in the genus Claviceps, is a primary disease concern in irrigated grass seed production systems of eastern Oregon. The species C. purpurea sensu stricto (Fr.) Tul., is the primary causal agent of ergot affecting cool-season grass seed crops in Oregon (Alderman 1991; Alderman et al. 1998; Scott et al. 2015). Ergot infection strictly occurs during host flowering and specifically, the pathogen infects unfertilized ovaries of host plants. Infection of floral ovaries results in the development of dark purplish-black sclerotia instead of seed. The disease negatively affects the grass seed industry by reducing yield, hindering seed cleaning and certification efforts, and preventing the sale of seed and seed byproducts including screenings and pellets. Even a small amount of ergot ( $0.5 \%$ incidence) can result in losses of up to $9 \%$ during cleaning (Alderman et al. 1996). Highly infected seed lots must be cleaned several times to remove ergot sclerotia and, in

${ }^{\dagger}$ Corresponding author: J. K. S. Dung; jeremiah.dung@oregonstate.edu

Funding: Financial support for this research was provided by the Oregon Seed Council/ODA Alternatives for Field Burning Research Financial Assistance Program, the Columbia Basin Grass Seed Association, and the Jefferson County Seed Growers Association.

*The $\boldsymbol{e}$-Xtra logo stands for "electronic extra" and indicates that supplementary materials and supplementary data are published online.

The author(s) declare no conflict of interest.

(c) 2020 The American Phytopathological Society severe situations, up to $40 \%$ of marketable seeds can be lost during the cleaning process. Considering the large amount of seed produced annually in Oregon (United States Department of Agriculture-National Agricultural Statistics Service 2017), a small amount of ergot in a seed lot can lead to substantial economic losses.

The ergot disease cycle begins in the spring, when overwintered soilborne sclerotia germinate to produce capitula, from which airborne sexual ascospores are released that infect unfertilized flowers. The ergot pathogen is considered to be homothallic based on both molecular data (Scott et al. 2015) and observations that infection by a single homokaryotic spore is enough to complete the pathogen's life cycle (Esser and Tudzynski 1978). Several days after infection, secondary inoculum in the form of asexual conidia are exuded from infected ovaries in a substance called honeydew. The conidia can be splash-dispersed to healthy flowers by rain or irrigation, and can be mechanically dispersed through plant-toplant contact or via insects, all of which can lead to multiple infection cycles during anthesis (Alderman 2006; Butler et al. 2001; Kaur et al. 2019; Menzies and Turkington 2015). Sclerotia are ultimately formed after infection of the ovaries, which fall to the ground during harvest and serve as overwintering structures of the pathogen. In one study, 4 to 120 sclerotia $\mathrm{m}^{-2}$ were found in perennial ryegrass fields after harvest, suggesting that sclerotia and ascospores can be significant sources of primary inoculum (Dung et al. 2016). However, since the pathogen has a wide host range among grassy crops and weeds in North America (Alderman et al. 2004), earlier flowering hosts such as cereal rye can become infected early in the spring and serve as reservoirs of conidia, which in turn can serve as sources of primary inoculum for later flowering grass seed crops (Dung et al. 2016). A better understanding of the reproductive biology of $C$. purpurea and the epidemiology of ergot would help improve disease management.

Previous studies have used random amplified microsatellites, random amplified polymorphic DNA (RAPD), and amplified fragment length polymorphism analyses to examine the genetic 
diversity of several Claviceps species, specifically C. africana (Pažoutová and Frederickson 2005; Tooley et al. 2000), C. sorghicola (Tooley et al. 2000), and C. purpurea (Fisher et al. 2005; Jungehülsing and Tudzynski 1997). The study by Fisher et al. (2005) focused on $C$. purpurea populations infecting hosts in salt marshes environments, a group that is now recognized as $C$. spartinae. Jungehülsing and Tudzynski (1997) used RAPD markers to identify variation among 29 C. purpurea isolates collected from various parts of Europe. Consequently, few studies exist on the genetic diversity of C. purpurea in the United States, or Claviceps populations affecting grass seed production systems. Gilmore et al. (2016) developed and utilized microsatellite markers and was able to distinguish three separate but closely related groups among $63 C$. purpurea isolates collected from Kentucky bluegrass and perennial ryegrass in Oregon. However, more research is needed to understand the population genetic diversity of $C$. purpurea in grass seed production systems at smaller spatial and temporal scales.

Despite the historical significance and widespread nature of ergot in agriculture, the relative importance of ascospores and conidia in the epidemiology of ergot remains unclear in many crops. A better understanding of the contribution of ascospores and conidia in ergot epidemics is essential since different strategies would be required to manage the two different types of inoculum. Extensive surveys of ergot incidence and severity in perennial ryegrass seed fields observed significant clustering and a nonrandom distribution of the disease in fields (Dung et al. 2016), but it was not determined if disease foci were due to primary infection by ascospores, secondary infection by conidia, or both. Therefore, the objectives of this study were (i) to quantify and characterize the genetic and genotypic diversity of $C$. purpurea populations on two host species from two production regions; and (ii) explore the genetic spatial structure of $C$. purpurea populations among and within individual plants, fields, and host species/grass seed production regions in order to determine the relative contribution of ascospores and conidia at different spatial scales in cool-season grass seed crops in Oregon.

\section{MATERIALS AND METHODS}

Field sampling and isolate collection. Two perennial ryegrass seed production fields near Hermiston, OR (HE1 and HE2) situated $4.3 \mathrm{~km}$ apart were sampled on 5 July 2017. Two Kentucky bluegrass seed production fields near Madras, OR (MA1 and MA2) and situated $1.4 \mathrm{~km}$ apart were sampled on 7 July 2017. Fields HE1 and HE2 were planted to cultivar Pavilion, while MA1 and MA2 were planted to cultivars Rockstar and Deep Blue, respectively. Fields HE1, HE2, and MA2 were irrigated using center pivot irrigation systems and sampled along five randomly placed transects that extended $72 \mathrm{~m}$ from the center of the field and were at least $72^{\circ}$ apart. Field MA1 was irrigated using a linear wheel line irrigation system and sampled along six linear transects spaced equally throughout the field. Plants were sampled from quadrats placed $10 \mathrm{~m}$ apart along each transect. This type of sampling method was used because the disease was not uniformly or randomly distributed within fields (Dung et al. 2016). From each plant, two sclerotia from different positions in the seed head were randomly selected for isolation. Sclerotia were surface-sterilized in $70 \%$ ethanol for $10 \mathrm{~s}$ followed by $0.5 \% \mathrm{NaOCl}$ for $1 \mathrm{~min}$, rinsed in sterile distilled water twice and air-dried in a laminar flow hood. The surface-sterilized sclerotia were broken in half and plated broken-side down on $1.5 \%$ water agar amended with streptomycin sulfate $(200 \mathrm{mg} / \mathrm{liter})$ and incubated for 3 days in the dark at room temperature (Dung et al. 2018). Hyphal-tipped isolates were stored on one-quarter strength potato dextrose agar (PDA) slants. Onehundred-two and 124 isolates were collected from 51 Kentucky bluegrass and 62 perennial ryegrass plants, respectively (Supplementary Fig. S1). The 226 isolates of $C$. purpurea in the study were assigned a priori to one of four populations based on the host species/grass seed production region (Kentucky bluegrass/Madras or perennial ryegrass/Hermiston) and fields (two fields for each host species/grass seed production region).

DNA extraction and isolate identification. Genomic DNA was extracted from actively growing 3-week-old PDA cultures of each isolate using a glass bead disruption protocol followed by phenol-chloroform extraction, according to Dobinson et al. (2000). DNA was diluted in sterile distilled water, quantified using a Nanodrop 2000C spectrophotometer (Nanodrop Products, Wilmington, DE), and stored at $-20^{\circ} \mathrm{C}$.

The identification of isolates as $C$. purpurea sensu stricto was confirmed by polymerase chain reaction (PCR) amplification and sequencing of the internal transcribed spacer (ITS) region of the rDNA. Each 20- $\mu$ l reaction contained the following: $10 \mu \mathrm{l}$ of $2 \times$ GoTaq Colorless Mastermix (Promega, Madison, WI), $0.5 \mu \mathrm{l}$ of $10 \mu \mathrm{M}$ each of primers ITS1 and ITS4 (White et al. 1990), $5 \mathrm{ng}$ of genomic DNA template, and $8 \mu \mathrm{l}$ of sterile distilled water. The thermal cycler (Eppendorf AG, Hamburg, Germany) was programmed with an initial denaturation of $95^{\circ} \mathrm{C}$ for $3 \mathrm{~min}$ followed by 35 cycles of $95^{\circ} \mathrm{C}$ for $30 \mathrm{~s}, 55^{\circ} \mathrm{C}$ for $30 \mathrm{~s}, 72^{\circ} \mathrm{C}$ for $1 \mathrm{~min}$, and a final extension at $72^{\circ} \mathrm{C}$ for $10 \mathrm{~min}$. A 5- $\mu$ l sample of each PCR product was stained with GelRed (Biotium Inc, Fremont, CA) and run on a $1 \%$ agarose gel for viewing under ultra-violet light.

Samples for sequencing were prepared as described by Dung et al. (2011) and sequenced in both directions by Elim Biopharmaceuticals, Inc. (Hayward, CA). Paired forward and reverse sequences were quality checked, aligned, and manually edited using SeqTrace (Stucky 2012) to obtain consensus sequences. ITS sequences were compared with known sequences in GenBank database using BLAST available from NCBI website (https:// www.ncbi.nlm.nih.gov/).

Microsatellite genotyping. Twelve previously published polymorphic loci (Gilmore et al. 2016) were used to genotype isolates from the $C$. purpurea populations (Table 1). Forward primers were amended with an M13-tail sequence (TGTAAAAC GACGGCCAGT) and fluorescently labeled with either FAM, NED, HEX, or PET (Thermo Fisher Scientific; Waltham, MA) (Schuelke 2000). Reverse primers were labeled with a PIG-tail sequence (GTTT) (Brownstein et al. 1996; Schuelke 2000). PCR reactions contained $0.5 \mu \mathrm{l}$ of template DNA $(\sim 5 \mathrm{ng}), 0.1 \mu \mathrm{l}$ of $10 \mu \mathrm{M}$ forward primer, $0.5 \mu \mathrm{l}$ of $10 \mu \mathrm{M}$ reverse primer, $0.5 \mu \mathrm{l}$ of $10 \mu \mathrm{M}$ fluorescently labeled M13 primer, $5 \mu$ l of Master mix, and $3.4 \mu \mathrm{l}$ of sterile distilled water in a total volume of $10 \mu \mathrm{l}$. Thermocycler amplifications were conducted with a touchdown PCR protocol consisting of an initial denaturing step of $94^{\circ} \mathrm{C}$ for $3 \mathrm{~min}$; 10 cycles of $94^{\circ} \mathrm{C}$ for $40 \mathrm{~s}, 62^{\circ} \mathrm{C}$ for $45 \mathrm{~s}$ (decreasing the annealing temperature by $1.0^{\circ} \mathrm{C}$ per cycle), and $72^{\circ} \mathrm{C}$ for $45 \mathrm{~s}$; followed by 20 cycles of $94^{\circ} \mathrm{C}$ for $40 \mathrm{~s}, 52^{\circ} \mathrm{C}$ for $45 \mathrm{~s}$, and $72^{\circ} \mathrm{C}$ for $45 \mathrm{~s}$; eight cycles of $94^{\circ} \mathrm{C}$ for $40 \mathrm{~s}, 53^{\circ} \mathrm{C}$ for $45 \mathrm{~s}$, and $72^{\circ} \mathrm{C}$ for $45 \mathrm{~s}$; and a final extension of $72^{\circ} \mathrm{C}$ for $30 \mathrm{~min}$ (Gilmore et al. 2016). Capillary electrophoresis of amplicons was performed using an ABI 3730 genetic analyzer (Applied Biosystems, Waltham, MA) at the Oregon State University Center for Genome Research and Biocomputing (Corvallis, OR). Alleles were scored using PeakScanner v2.0 (Life Technologies Corporation, Carlsbad, CA) and summarized in an Excel (Microsoft Corporation, Redmond, WA) spreadsheet for further analyses. Twenty percent of the isolates (47 of 226) were randomly chosen to repeat the above procedure to ensure the reproducibility of the data.

Analyses of genetic and genotypic diversity. Raw allele length data were statistically binned into allelic classes using the Microsoft Excel macro FLEXIBIN V2 (Amos et al. 2007). Multilocus genotypes (MLGs) were identified using the "poppr" package (Kamvar et al. 2014, 2015) in R (R Core Team 2016) and clone correction was performed for each of the four predefined populations (MA1, MA2, HE1, and HE2). The average number of alleles per locus $\left(N_{\mathrm{a}}\right)$, the effective number of alleles $\left(N_{\mathrm{e}}\right)$, expected $\left(H_{\mathrm{e}}\right)$ and observed heterozygosity $\left(H_{\mathrm{o}}\right)$, Nei's genotypic diversity 
$\left(H_{\text {exp }}\right)$, and standardized index of association $\left(\bar{r}_{\mathrm{d}}\right)$ were calculated using "poppr" in R. Pairwise population differentiation and gene flow were analyzed using the Microsoft Excel macro GenAlEx v6.5 (Peakall and Smouse 2012).

Linkage disequilibrium in $C$. purpurea was assessed using the standardized index of association $\left(\bar{r}_{\mathrm{d}}\right)$ (Agapow and Burt 2001). Linkage disequilibrium was calculated separately for each population based on 9,999 permutations for both the original and clonecorrected data in "poppr". The null hypothesis $\left(\bar{r}_{\mathrm{d}}=0\right.$, linkage equilibrium) was tested in which the association between alleles is determined to be random, which infers meiosis via sexual reproduction. In contrast, clonally reproducing organisms tend to have $\bar{r}_{\mathrm{d}}$ values significantly larger than zero (i.e., linkage disequilibrium). In addition, pairwise $\bar{r}_{\mathrm{d}}$ values were calculated over all pairs of loci to ensure that any linkage disequilibrium that was detected was not due to a single pair of loci and were not correlated with physical distance between any loci located on same chromosome. For this effort, the SSR primers were mapped onto the genome of $C$. purpurea strain 20.1 (GenBank assembly accession GCA_000347355.1) (Schardl et al. 2013) using the "Biostrings" package (Pagès et al. 2019) in R. Physical distances of loci within the same contigs were calculated by subtracting the corresponding positions of the loci. Pearson correlation coefficients were determined between the physical distance of pairwise loci on the same contig and the corresponding $\bar{r}_{\mathrm{d}}$ in each of the four populations using $\mathrm{R}$.

Analyses of population structure and genetic differentiation. For the analysis of population structure, the Bayesian approach in Structure v2.3.4 (Pritchard et al. 2000) was implemented using clone-corrected data. For each value of $K$ (range 1 to 10), 30 independent runs were conducted with a burn-in period of 200,000 followed by 600,000 Markov Chain Monte Carlo repetitions. Other parameters were set as the default. Structure Harvester web v0.6.94 (Earl and vonHoldt 2012) was used to estimate the most probable value of $K$ (number of clusters) with the delta $K$ method (Evanno et al. 2005), which was visualized using Pophelper web v1.0.10 (Francis 2017).

To visualize the genetic distance and population structure, principal coordinate analysis ( $\mathrm{PCoA}$ ) was performed and a minimum spanning network (MSN) was constructed based on Bruvo's distance (Bruvo et al. 2004). PCoA was conducted on clone-corrected data using GenAlEx, while the MSN was constructed using the original data set and the "poppr" package in R. Analysis of molecular variance (AMOVA) was conducted with ARLEQUIN v3.5.2 (Excoffier and Lischer 2010) using both the original and clone-corrected data. For AMOVA, the following variance components were calculated: (i) among host species/grass seed production regions $\left(F_{\mathrm{ct}}\right)$; (ii) among fields within production regions $\left(F_{\mathrm{sc}}\right)$; and (iii) among plants within fields $\left(F_{\mathrm{st}}\right)$. All AMOVA analyses were computed using 10,000 permutations at $\alpha=0.05$.

\section{RESULTS}

Analyses of genetic and genotypic diversity. All the ergot isolates collected in this study were identified as $C$. purpurea sensu stricto. Clone correction was performed at the level of the populations (MA1, MA2, HE1, and HE2), resulting in 29 isolates being removed from the original data set ( 13 clones from field MA1, eight clones from field MA2, five clones from field HE1, and three clones from field HE2) and 194 MLGs (Table 2). Among the clonal isolates sampled, $96.6 \%$ (28 out of 29) were the same MLG as the other isolate collected from the same seed head (data not shown). Clonecorrected data (197 isolates with 194 MLGs) were used in subsequent analyses.

The number of alleles ranged between 2 for primer pair Cpur24 and 15 for primer pair Cpur56 (Table 1). Thirty-four private alleles $\left(P_{\mathrm{a}}\right)$ were observed among the four designated populations, with $P_{\mathrm{a}}$ values ranging between 2 and 5 in HE1 and HE2, respectively, to 13 and 14 in MA1 and MA2, respectively (Table 2). The ShannonWeiner index of MLG diversity $(H)$ ranged from 3.43 in MA1, to 4.23 in HE1. Mean genotypic diversity corrected for sample size $\left(H_{\text {exp }}\right)$ across all populations was 0.542 and ranged from 0.447 in HE1 to 0.572 in MA1 (Table 2).

The standardized index of association varied among the four populations for both original and clone-corrected datasets. The $\bar{r}_{\mathrm{d}}$ value observed for the MA2 population did not differ significantly from zero $(P=0.08$ and 0.24 for original and clone-corrected datasets, respectively), while $\bar{r}_{\mathrm{d}}$ values in the MA1, HE1 and HE2 populations were significantly different from zero for both datasets (all $P<0.05$ ) (Table 2). The patterns of linkage disequilibrium were not due to a single pair or just a few pairs of loci (Fig. 1; Table 3) nor were they related to physical distances between loci according to the correlation coefficients (Supplementary Table S1).

TABLE 1. Sequences, repeat motif, allelic size range, and number of alleles of 12 microsatellite markers (Gilmore et al. 2016) used to identify multilocus genotypes of Claviceps purpurea

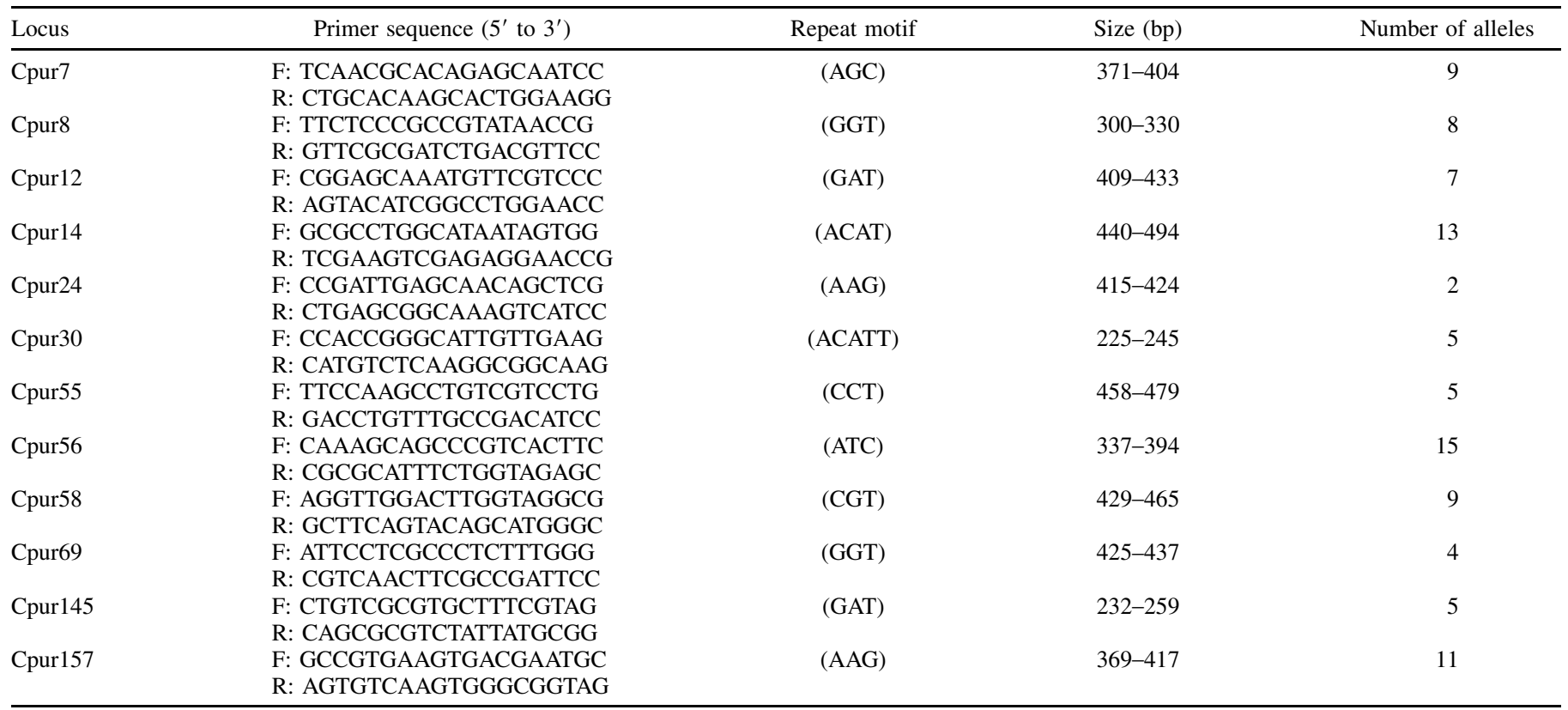


Analyses of population structure and genetic differentiation. The presence of two genetic clusters $(\Delta K=2)$ best explained the population structure of $C$. purpurea populations across the two host species and grass seed production regions (Fig. 2; Supplementary Fig. S2), and the suggested clusters corresponded to the two host species/grass seed production regions that were sampled. Potential admixture was detected in only three MLGs collected from perennial ryegrass in Hermiston (Fig. 2). When $\Delta K=3$ was considered as a possible clustering option for these populations and compared with $\Delta K=2$, all MLGs in the third cluster were from the Madras/Kentucky bluegrass population.
AMOVA was performed by grouping $C$. purpurea sensu stricto populations into two groups based on the two host species/grass seed production regions. Because the hierarchical sampling within each plant resulted in two separate isolates from each seed head, within-samples-variance was also calculated to measure genetic differences between two isolates from the same plant. For the full, non-clone-corrected dataset, approximately half of the genetic variation $(49.65 \%)$ was attributed to differences between the two isolates sampled from a single seed head of a plant (Table 4). After clone correction, $66.22 \%$ of the genetic variation was explained by differences between two MLGs collected from the same plant

TABLE 2. Summary of the genotypic and genetic diversity statistics from four populations of Claviceps purpurea using 12 microsatellite loci ${ }^{\mathrm{a}}$

\begin{tabular}{|c|c|c|c|c|c|c|c|c|c|c|}
\hline Population $^{\mathrm{b}}$ & $n$ & MLG & Clonal fraction & Private alleles & $H$ & $\lambda$ & E.5 & $H_{\exp }$ & $\bar{r}_{\mathrm{d}}$ & $\bar{r}_{\mathrm{d}}($ clone-corrected $)$ \\
\hline MA1 & 44 & 31 & 0.30 & 14 & 3.43 & 0.97 & 1 & 0.57 & $0.124^{*}$ & $0.122 *$ \\
\hline MA2 & 58 & 50 & 0.14 & 13 & 3.89 & 0.98 & 1 & 0.45 & 0.013 & 0.007 \\
\hline HE1 & 74 & 69 & 0.07 & 2 & 4.23 & 0.99 & 1 & 0.45 & $0.016^{*}$ & $0.016^{*}$ \\
\hline HE2 & 50 & 47 & 0.06 & 5 & 3.81 & 0.98 & 1 & 0.49 & $0.018 *$ & $0.016^{*}$ \\
\hline Overall & 226 & 194 & 0.13 & 34 & 5.27 & 1.00 & 1 & 0.54 & 0.045 & 0.043 \\
\hline
\end{tabular}

${ }^{a}$ MLG, multilocus genotypes; $H$, Shannon-Wiener index of multilocus genotype (MLGs) diversity; $\lambda$, Simpson's index; E.5, evenness; $H_{\text {exp }}$, Nei's unbiased gene diversity; and $\bar{r}_{\mathrm{d}}$, standardized index of association, which is used to detect linkage disequilibrium. $\bar{r}_{\mathrm{d}}$ values were based on either the original data (226 MLGs) or clone-corrected (194 MLGs) of Claviceps purpurea and based on 12 microsatellite loci separately for each of the four populations. Data were obtained based on 9,999 permutations. The assumption of random recombination is accepted at a $P$ value $>0.05$ or rejected at a $P$ value $<0.05$. * Indicates significant linkage disequilibrium at $P \leq 0.05$, based on $\bar{r}_{\mathrm{d}}$.

b Populations were derived from collections of sclerotia from Kentucky bluegrass seed fields in Madras, OR and designated as MA1 and MA2; populations from fields HE1 and HE2 were collected from two commercial perennial ryegrass seed fields near Hermiston, OR.

A

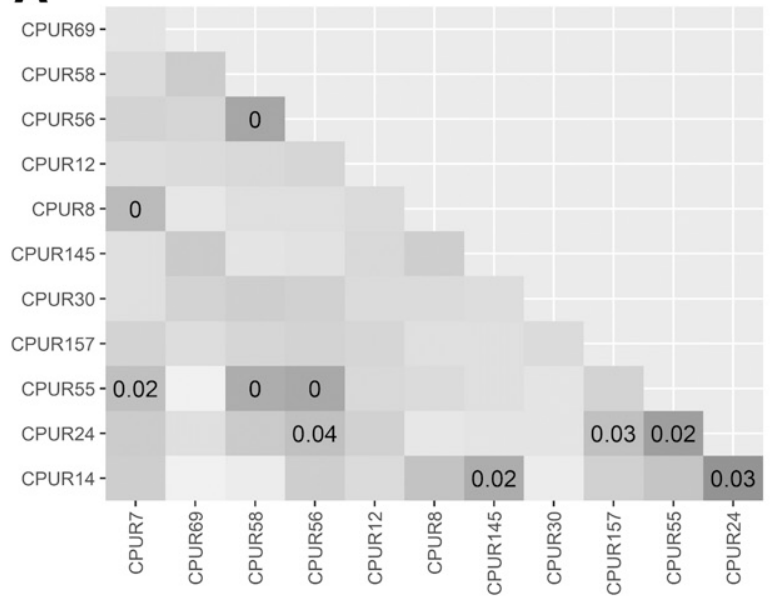

C

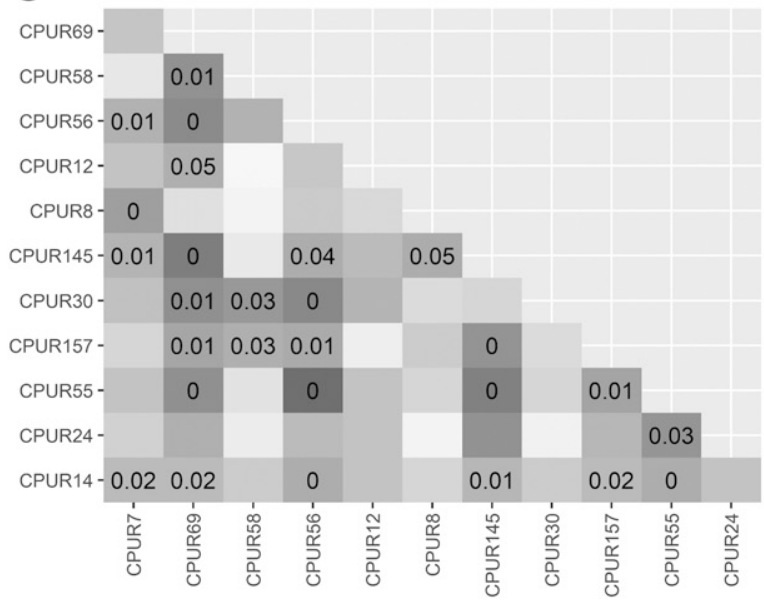

B

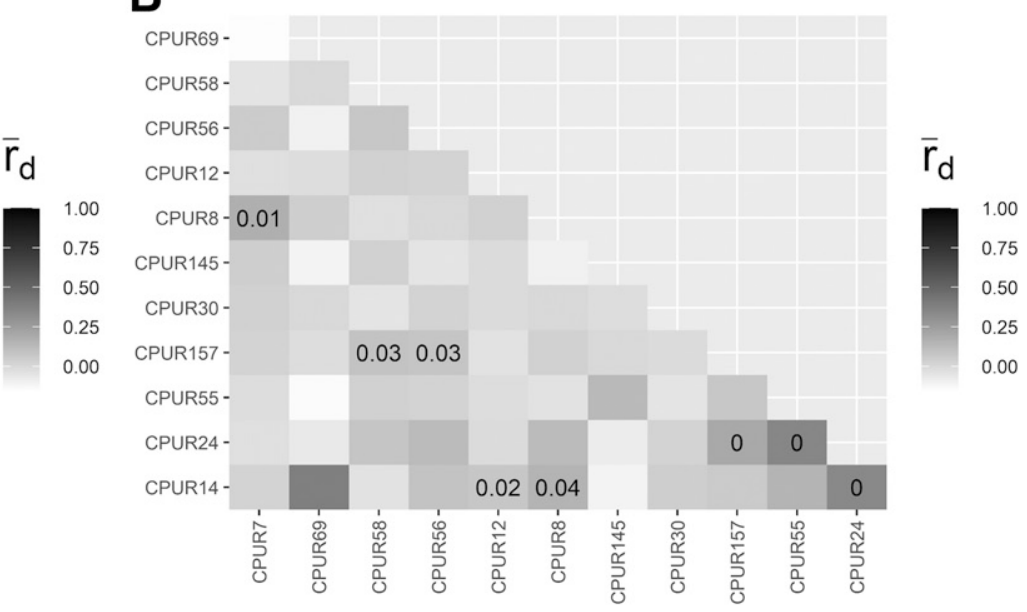

D

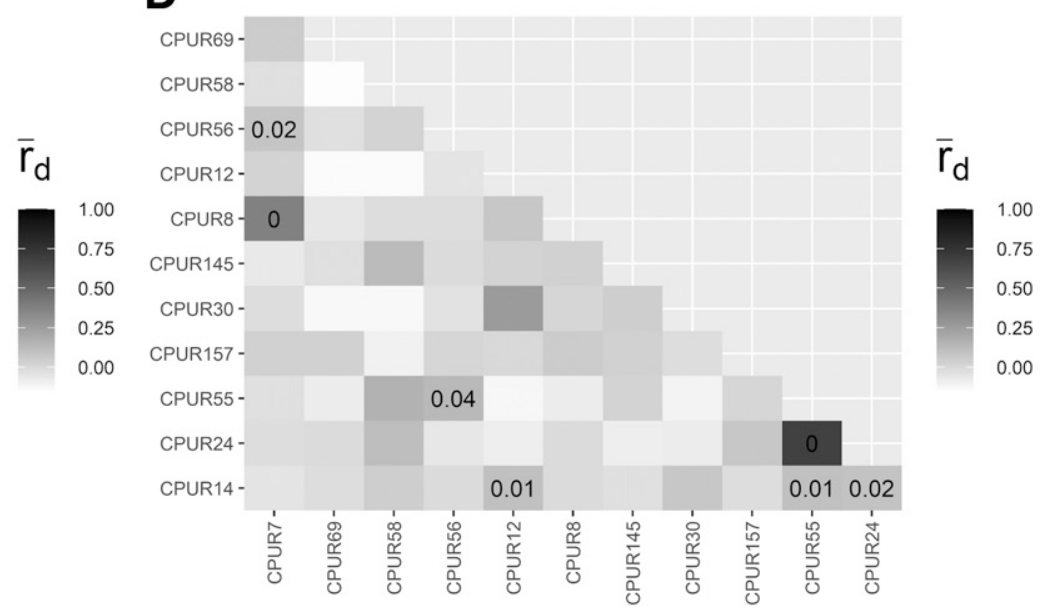

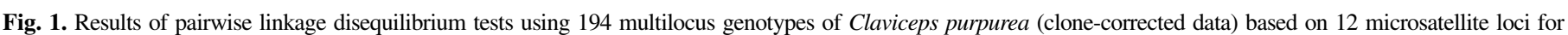

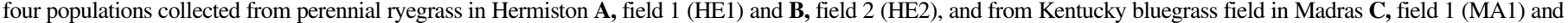

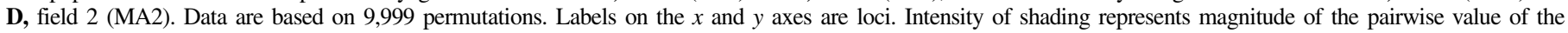

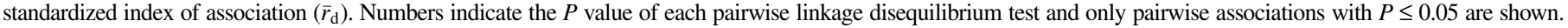


(Table 4). Within a host species/grass seed production region, none of the genetic variation could be explained by differences between populations from the two fields in either the full or the clonecorrected data set (Table 4). Approximately 28 and $12 \%$ of the variation could be attributed to differences among MLGs collected from plants within each field for both the full and clone-corrected data sets, respectively (Table 4), and between 21.49 and $21.84 \%$ of the variation was due to genetic differences between the populations from the two host species/grass seed production regions $\left(F_{\mathrm{ct}}=0.22\right.$ for both the full and clone-corrected data).

Pairwise population differentiation $\left(F_{\text {st }}\right)$ indicated significant genetic differentiation among isolates from the two fields representing each host species/production region $\left(F_{\mathrm{st}}=0.28 ; P<\right.$ $0.05)$, but populations from fields associated within the same host species/production region were not significantly different $\left(F_{\mathrm{st}}=\right.$ $0.012 ; P>0.05)$ (Table 5). The MA2 and HE1 populations were the most differentiated $\left(F_{\text {st }}=0.34\right)$, while the two populations in Hermiston were the least differentiated $\left(F_{\text {st }}=0\right)$.

Results from principle coordinate analysis (PCoA) were consistent with STRUCTURE analysis and suggested that two genetic clusters were present among the sampled MLGs (Fig. 3). The first two axes only explained $23.24 \%$ of the observed variation, which indicated that more of the variation among MLGs was attributed to genetic differences among populations collected at the plant level and was consistent with the results obtained from AMOVA. PCoA and minimum spanning networks indicated that the Kentucky bluegrass/Madras populations grouped together and clustered separately from the perennial ryegrass/Hermiston populations, with the exception of a few MLGs (Fig. 3; Supplementary Fig. S3).

\section{DISCUSSION}

C. purpurea isolates were previously designated as genotypes G1, G2, and G3 based on differences in morphology, molecular markers, alkaloid profiles, and habitats (Pažoutová et al. 2000). These three genotypes are now recognized as $C$. purpurea sensu stricto, C. humidiphila, and C. spartinae, respectively. Although at least two Claviceps species, C. purpurea sensu stricto and C. humidiphila (Pažoutová et M. Kolařík) are reported to cause ergot in Kentucky bluegrass (Douhan et al. 2008; Pažoutová et al. 2000; Scott et al. 2015), all of the Claviceps isolates collected in this study were identified as $C$. purpurea sensu stricto based on ITS region sequences. Only $C$. purpurea sensu stricto is reported to infect perennial ryegrass, which is consistent with our current and previous results (Alderman et al. 2015; Scott et al. 2015).
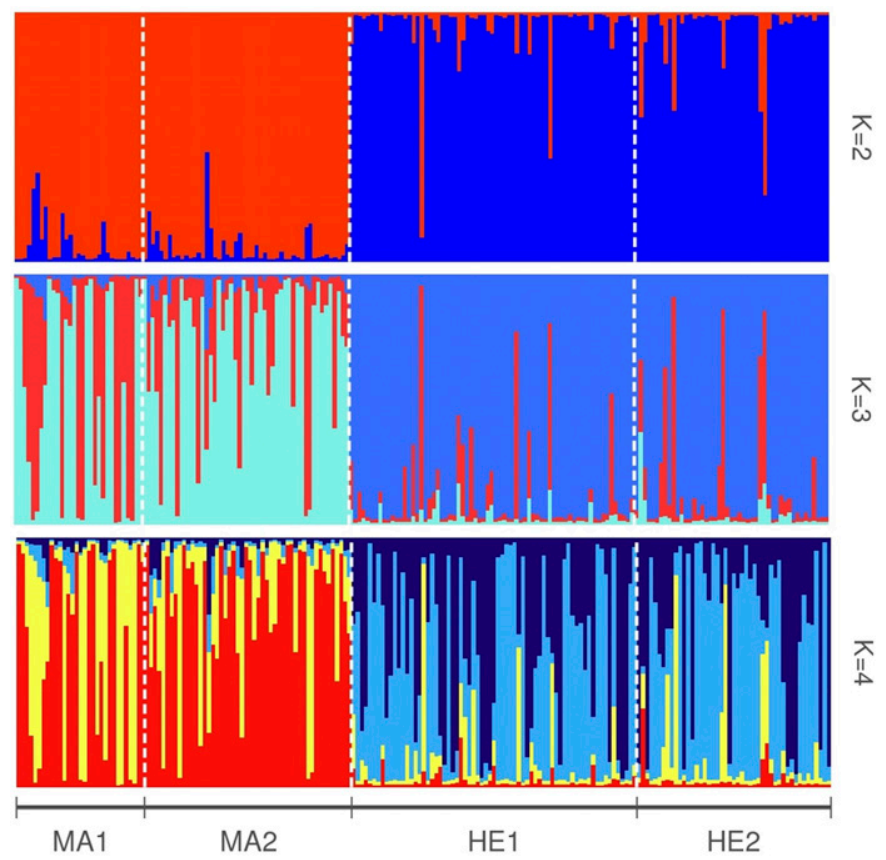

Fig. 2. Population structure (based on $K=2$, 3, or 4 genetic clusters) of 194 multilocus genotypes (MLGs) of Claviceps purpurea (clone-corrected data) from two grass seed production regions in Oregon, Madras (MA) and Hermiston (HE), and two fields in each region (1 and 2) based on genotyping using 12 microsatellite loci. Each population is separated by a dashed white line and each bar corresponds to an individual MLG. Bars that split into different colors are indicative of admixture and the proportion of colors represents the membership of each MLG to one of the designated clusters.

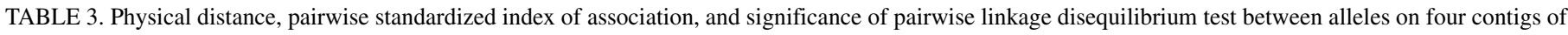
Claviceps purpurea in four population samples (MA1, MA2, HE1, and HE2) ${ }^{\mathrm{a}}$

\begin{tabular}{|c|c|c|c|c|c|}
\hline Locus pair ${ }^{b}$ & Distance $(\mathrm{kb})$ & MA1 & MA2 & HE1 & HE2 \\
\hline \multicolumn{6}{|l|}{ CAGA01000039c } \\
\hline Cpur7 versus Cpur8 & 4.2 & $0.24 *$ & $0.37 *$ & $0.12 *$ & $0.17 *$ \\
\hline \multicolumn{6}{|l|}{ CAGA01000053.1 } \\
\hline Cpur12 versus Cpur14 & 11.1 & 0.09 & $0.10^{*}$ & -0.01 & $0.07 *$ \\
\hline Cpur12 versus Cpur24 & 78.8 & 0.09 & -0.09 & 0.03 & -0.01 \\
\hline Cpur12 versus Cpur30 & 108.8 & 0.15 & 0.26 & -0.01 & -0.01 \\
\hline Cpur14 versus Cpur24 & 67.7 & 0.09 & $0.09 *$ & $0.29 *$ & $0.34^{*}$ \\
\hline Cpur14 versus Cpur30 & 97.7 & 0.05 & 0.07 & -0.08 & 0.04 \\
\hline Cpur24 versus Cpur30 & 5.4 & -0.10 & -0.08 & -0.05 & 0.02 \\
\hline \multicolumn{6}{|l|}{ CAGA01000054 } \\
\hline Cpur55 versus Cpur56 & 44.3 & $0.46^{*}$ & $0.13^{*}$ & $0.20 *$ & 0.02 \\
\hline Cpur55 versus Cpur58 & 38.9 & -0.04 & 0.16 & $0.18^{*}$ & 0.03 \\
\hline Cpur56 versus Cpur58 & 46.2 & $0.16^{*}$ & 0.02 & $0.21 *$ & 0.07 \\
\hline \multicolumn{6}{|l|}{ CAGA01000060.1 } \\
\hline Cpur145 versus Cpur157 & 30.0 & $0.29 *$ & 0.03 & -0.03 & $<0.01$ \\
\hline Over all loci & & $0.12 *$ & 0.007 & $0.016^{*}$ & $0.016^{*}$ \\
\hline
\end{tabular}

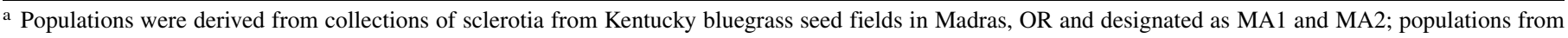
fields HE1 and HE2 were collected from two commercial perennial ryegrass seed fields near Hermiston, OR. * Indicates significant linkage disequilibrium at $P \leq$ 0.05 , based on $\bar{r}_{\mathrm{d}}$.

b Loci were defined by Gilmore et al. (2016).

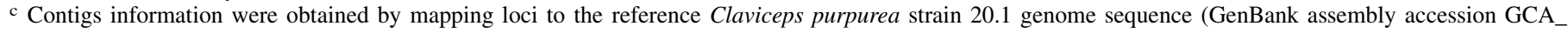
000347355.1) published by Schardl et al. (2013). 
Based on this study, two discrete groups of $C$. purpurea were identified from two different cool season seed cropping systems in Oregon. The population from Kentucky bluegrass in Madras was genetically distinct from the population collected from perennial ryegrass in Hermiston, with the exception of a few isolates. However, it is not clear if the genetic differentiation observed was due to host or geographical factors because of sampling limitations in the two grass seed production regions (perennial ryegrass is not grown in Madras and is the primary grass seed crop in Hermiston). Differences in host specificity or aggressiveness among $C$. purpurea populations have not been extensively studied but warrant future research.

As a homothallic species (Esser and Tudzynski 1978; Scott et al. 2017), genetically identical haploid cells of Claviceps can fuse during sexual reproduction, resulting in haploid selfing (Billiard et al. 2012) and a seemingly clonal population structure. Alternatively, homothallic fungi can also reproduce sexually via outcrossing. For several Sclerotinia species, including S. sclerotiorum sband $S$. subarctica, which have a similar reproductive cycle to C. purpurea that is based on homothallic sexual reproduction through carpogenic germination of sclerotia, populations were considered heavily clonal with evidence that outcrossing was infrequent based on measures of linkage disequilibrium (Anderson and Kohn 1995; Clarkson et al. 2017; Hambleton et al. 2002; Winton et al. 2006). However, one study used linkage disequilibrium decay in $S$. sclerotiorum to conclude that outcrossing in S. sclerotiorum may be much more common than previous studies suggested (Attanayake et al. 2014). In our study, the standardized index of association varied among populations in the four fields. The relatively large clonal fraction (0.30) and significant $\bar{r}_{\mathrm{d}}$ values observed for both the original and clone-corrected datasets in the MA1 population suggest that asexual conidia played a role in disease spread and development in this field; however, the significant $\bar{r}_{\mathrm{d}}$ values observed for the HE1 and HE2 populations, which had lower clonal fractions (0.07 and 0.06, respectively) may be due to the homothallic nature of the fungus. In contrast, the nonsignificant $\bar{r}_{\mathrm{d}}$ values observed in the MA2 population for both the original and clone-corrected datasets indicate that sexual ascospores were a major source of ergot infections, and that the population experienced outcrossing. Nevertheless, a mixed mode of reproduction was likely occurring in MA2, as evidenced by the moderate clonal fraction observed in this field (0.14).

Mean clonal fractions of $C$. purpurea populations in Kentucky bluegrass grown Madras and perennial ryegrass grown in Hermiston were 0.21 and 0.06 , respectively, and most clonal isolates ( 28 out of 29) were collected from the same seed head. These results suggest that conidia can play an important role in secondary spread at small spatial scales (i.e., within seed heads or between plants that are adjacent to each other). However, based on the collective results, ascospores appeared to be the main drivers of the epidemic, at least at the beginning of the season, as the greatest degree of diversity was observed among sclerotia collected from the same plant. In addition, none of the variation could be attributed to differences between fields within locations. This, together with the relatively low clonal fractions observed in three out of four fields, suggests that airborne ascospores were the principal source of inoculum for disease spread between fields within a production region. These results support the hypothesis that asexual conidia are more important to ergot epidemiology at smaller spatial scales, which is likely via shortdistance splash and contact dispersal, while airborne ascospores are more important at larger spatial scales. Nevertheless, the potential exists for long-distance spread of conidia on or in foraging insects (Kaur et al. 2019). For instance, in this study, two clonal isolates from field MA2 were the same MLG as an isolate collected from field MA1, which was located approximately $1.4 \mathrm{~km}$ away (data not shown).

The clonal fraction observed in field MA1 (30\%) was greater than the other three populations, suggesting that conidia were responsible for at least $30 \%$ of the infections observed. Although ascospores are considered the primary source of inoculum and are often abundant in grass seed production systems, conidia-laden honeydew can also be produced in large quantities. Grass cultivars with long anthesis periods are, at least in theory, more prone to infection by conidia since there is more time for secondary infections to occur. Cultivars with later anthesis periods are also more likely to be infected by conidia that are produced by infected cultivars that flower and are infected earlier in the season. Weedy grass hosts, such as cereal rye (Secale cereale), which flower early and throughout the grass seed production season, can also support

TABLE 5. Pairwise population differentiation for Claviceps purpurea multilocus genotypes (MLGs) collected from two host species/grass seed production regions in Oregon ${ }^{\mathrm{a}}$

\begin{tabular}{lcccc}
\hline & MA1 & MA2 & HE1 & HE2 \\
\hline MA1 & - & & & \\
MA2 & $0.01^{\text {ns }}$ & - & & \\
HE1 & 0.30 & 0.34 & - & - \\
HE2 & 0.28 & 0.31 & $0.0^{\text {ns }}$ & - \\
\hline
\end{tabular}

a Populations were derived from collections of sclerotia from Kentucky bluegrass seed fields in Madras, OR and designated as MA1 and MA2; populations from fields HE1 and HE2 were collected from two commercial perennial ryegrass seed fields near Hermiston, OR. Isolate MLG identity was based on 12 microsatellite loci. $F_{\text {st }}$ values are based on 10,000 permutations. ns indicates not significant at $\alpha=0.05$.

TABLE 4. Hierarchical analysis of molecular variance for Claviceps purpurea isolates from four populations based on 12 microsatellite loci for both original and clone-corrected data

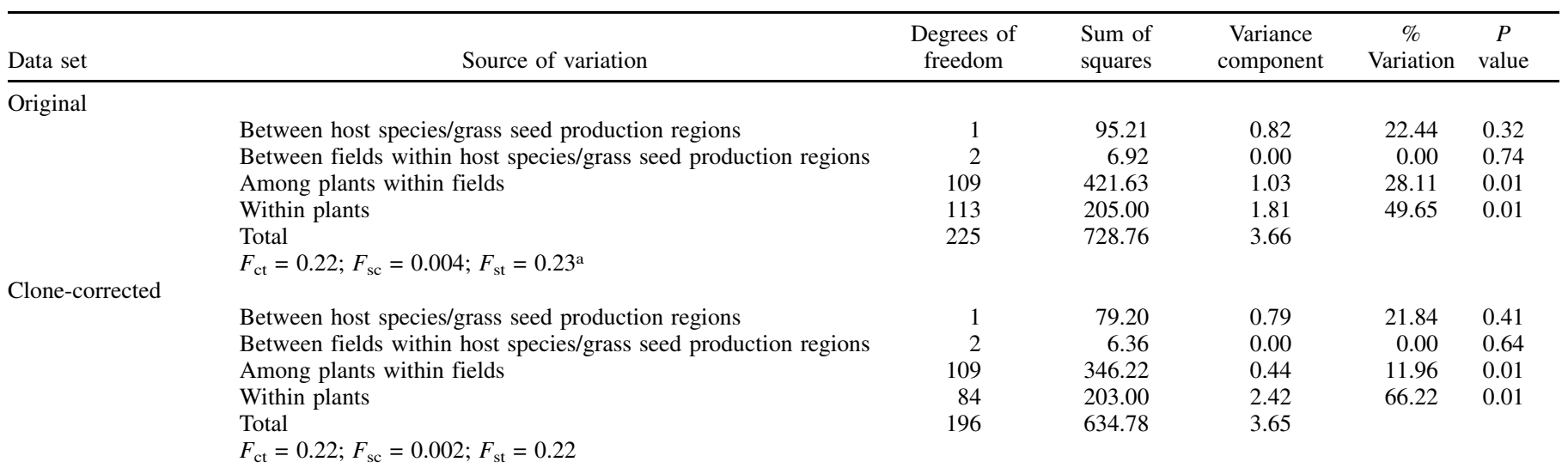

${ }^{\mathrm{a}} F_{\mathrm{ct}}$, the variance among host species (Poa pratensis and Lolium perenne)/grass seed production regions (Madras, OR and Hermiston, OR) relative to the total variance; $F_{\mathrm{sc}}$, the variance among fields within host species/grass seed production regions; and $F_{\mathrm{st}}$, the variance among plants within fields. 


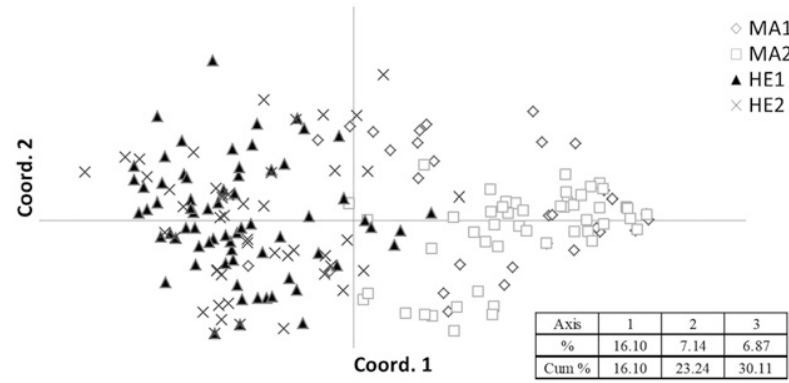

Fig. 3. Principal coordinate analysis of 194 multilocus genotypes of Claviceps purpurea (clone-corrected data) sampled from four populations in Oregon (two grass seed production regions, Madras [MA] and Hermiston [HE], and two fields in each region, 1 and 2).

early ergot infections and serve as sources of conidia (Dung et al. 2016).

This is the first study investigating the population structure of $C$. purpurea in cool-season grass seed crops of Oregon, and the results provide novel insights into the epidemiology of $C$. purpurea at different spatial scales in the state. Knowledge regarding the relative importance of ascospores and conidia in disease spread and epidemiology are essential toward designing strategies for improved management of ergot in cool-season seed crop production systems. The present study establishes methods to study the population structure of $C$. purpurea sensu stricto at different spatial scales but further research is needed to investigate the population structure of $C$. purpurea sensu stricto in additional locations, at additional spatial and temporal scales, in other crops, and in natural ecosystems.

\section{LITERATURE CITED}

Agapow, P. M., and Burt, A. 2001. Indices of multilocus linkage disequilibrium. Mol. Ecol. Notes 1:101-102.

Alderman, S. C. 1991. Assessment of ergot and blind seed diseases of grasses in the Willamette Valley of Oregon. Plant Dis. 75:1038-1041.

Alderman, S. C. 2006. Ergot: Biology and Control. https://www.ars.usda.gov/ SP2UserFiles/person/81/ErgotDVDtranscript.pdf

Alderman, S. C., Coats, D. D., and Crowe, F. J. 1996. Impact of ergot on Kentucky bluegrass grown for seed in northeastern Oregon. Plant Dis. 80: 853-855.

Alderman, S. C., Coats, D. D., Crowe, F. J., and Butler, M. D. 1998. Occurrence and distribution of ergot and estimates of seed loss in Kentucky bluegrass grown for seed in central Oregon. Plant Dis. 82:89-93.

Alderman, S. C., Halse, R. R., and White, J. F. 2004. A reevaluation of the host range and geographical distribution of Claviceps species in the United States. Plant Dis. 88:63-81.

Alderman, S. C., Walenta, D. L., Hamm, P. B., Martin, R. C., Dung, J., and Kosman, E. 2015. Afternoon ascospore release in Claviceps purpurea optimizes perennial ryegrass infection. Plant Dis. 99:1410-1415.

Amos, W., Hoffman, J. I., Frodsham, A., Zhang, L., Best, S., and Hill, A. V. S. 2007. Automated binning of microsatellite alleles: Problems and solutions. Mol. Ecol. Notes 7:10-14.

Anderson, J. B., and Kohn, L. M. 1995. Clonality in soilborne, plantpathogenic fungi. Annu. Rev. Phytopathol. 33:369-391.

Attanayake, R. N., Tennekoon, V., Johnson, D. A., Porter, L. D., del Rio-Mendoza, L., Jiang, D., and Chen, W. 2014. Inferring outcrossing in the homothallic fungus Sclerotinia sclerotiorum using linkage disequilibrium decay. Heredity 113:353-363.

Billiard, S., Lopez-Villavicencio, M., Hood, M. E., and Giraud, T. 2012. Sex, outcrossing and mating types: Unsolved questions in fungi and beyond. J. Evol. Biol. 25:1020-1038.

Brownstein, M. J., Carpten, J. D., and Smith, J. R. 1996. Modulation of nontemplated nucleotide addition by Taq DNA polymerase: Primer modifications that facilitate genotyping. Biotechniques 20:1004-1010.

Bruvo, R., Michiels, N. K., D’Souza, T. G., and Schulenburg, H. 2004. A simple method for the calculation of microsatellite genotype distances irrespective of ploidy level. Mol. Ecol. 13:2101-2106.

Butler, M. D., Alderman, S. C., Hammond, P. C., and Berry, R. E. 2001. Association of insects and ergot (Claviceps purpurea) in Kentucky bluegrass seed production fields. J. Econ. Entomol. 94:1471-1476.
Clarkson, J. P., Warmington, R. J., Walley, P. G., Denton-Giles, M., Barbetti, M. J., Brodal, G., and Nordskog, B. 2017. Population structure of Sclerotinia subarctica and Sclerotinia sclerotiorum in England, Scotland and Norway. Front. Microbiol. 8:490.

Dobinson, K. F., Harrington, M. A., Omer, M., and Rowe, R. C. 2000. Molecular characterization of vegetative compatibility group $4 \mathrm{~A}$ and $4 \mathrm{~B}$ isolates of Verticillium dahliae associated with potato early dying. Plant Dis. 84: 1241-1245.

Douhan, G. W., Smith, M. E., Huyrn, K. L., Westbrook, A., Beerli, P., and Fisher, A. J. 2008. Multigene analysis suggests ecological speciation in the fungal pathogen Claviceps purpurea. Mol. Ecol. 17:2276-2286.

Dung, J. K. S., Alderman, S. C., Walenta, D. L., and Hamm, P. B. 2016. Spatial patterns of ergot and quantification of sclerotia in perennial ryegrass seed fields in eastern Oregon. Plant Dis. 100:1110-1117.

Dung, J. K. S., Du Toit, L. J., and Johnson, D. A. 2011. Verticillium wilt of skullcap and potential for pathogen dissemination via seeds and stems. Plant Dis. 95:1147-1152.

Dung, J. K. S., Scott, J. C., Cheng, Q., Alderman, S. C., Kaur, N., Walenta, D. L., Frost, K. E., and Hamm, P. B. 2018. Detection and quantification of airborne Claviceps purpurea sensu lato ascospores from hirst-type spore traps using real-time quantitative PCR. Plant Dis. 102:2487-2493.

Earl, D. A., and vonHoldt, B. M. 2012. STRUCTURE HARVESTER: A website and program for visualizing STRUCTURE output and implementing the Evanno method. Conserv. Genet. Resour. 4:359-361.

Esser, K., and Tudzynski, P. 1978. Genetics of the ergot fungus Claviceps purpurea. Proof of a monoecious life-cycle and segregation patterns for mycelial morphology and alkaloid production. Theor. Appl. Genet. 53:145-149.

Evanno, G., Regnaut, S., and Goudet, J. 2005. Detecting the number of clusters of individuals using the software STRUCTURE: a simulation study. Mol. Ecol. 14:2611-2620

Excoffier, L., and Lischer, H. E. 2010. Arlequin suite ver 3.5: A new series of programs to perform population genetics analyses under Linux and Windows. Mol. Ecol. Resour. 10:564-567.

Fisher, A. J., Gordon, T. R., and Ditomaso, J. M. 2005. Geographic distribution and diversity in Claviceps purpurea from salt marsh habitats and characterization of Pacific coast populations. Mycol. Res. 109:439-446.

Francis, R. M. 2017. pophelper: An R package and web app to analyse and visualize population structure. Mol. Ecol. Resour. 17:27-32.

Gilmore, B. S., Alderman, S. C., Knaus, B. J., Bassil, N. V., Martin, R. C., Dombrowski, J. E., and Dung, J. K. S. 2016. Simple sequence repeat markers that identify Claviceps species and strain. Fungal Biol. Biotechnol. 3:1.

Hambleton, S., Walker, C., and Kohn, L. M. 2002. Clonal lineages of Sclerotinia sclerotiorum previously known from other crops predominate in 1999-2000 samples from Ontario and Quebec soybean. Can. J. Plant Pathol. 24:309-315.

Jungehülsing, U., and Tudzynski, P. 1997. Analysis of genetic diversity in Claviceps purpurea by RAPD markers. Mycol. Res. 101:1-6.

Kamvar, Z. N., Brooks, J. C., and Grünwald, N. J. 2015. Novel R tools for analysis of genome-wide population genetic data with emphasis on clonality. Front. Genet. 6:208.

Kamvar, Z. N., Tabima, J. F., and Grünwald, N. J. 2014. Poppr: An R package for genetic analysis of populations with clonal, partially clonal, and/or sexual reproduction. PeerJ 2:e281.

Kaur, N., Cating, R. A., Rondon, S. I., Scott, J. C., Alderman, S. C., Walenta, D. L., Frost, K. E., Hamm, P. B., and Dung, J. K. S. 2019. Dispersal potential of ergot spores by insects foraging in perennial ryegrass fields in the Columbia Basin of Oregon and Washington. Crop Forage Turfgrass Manage. 5:190020.

Menzies, J. G., and Turkington, T. K. 2015. An overview of the ergot (Claviceps purpurea) issue in western Canada: Challenges and solutions. Can. J. Plant Pathol. 37:40-51.

Pagès, H., Aboyoun, P., Gentleman, R., and DebRoy, S. 2019. Biostrings: Efficient manipulation of biological strings. $\mathrm{R}$ package version 2.52.0.

Pažoutová, S., and Frederickson, D. E. 2005. Genetic diversity of Claviceps africana on sorghum and Hyparrhenia. Plant Pathol. 54:749-763.

Pažoutová, S., Olšovská, J., Linka, M., Kolínská, R., and Flieger, M. 2000. Chemoraces and habitat specialization of Claviceps purpurea populations. Appl. Environ. Microbiol. 66:5419-5425.

Peakall, R., and Smouse, P. E. 2012. GenAlEx 6.5: Genetic analysis in Excel. Population genetic software for teaching and research-an update. Bioinformatics 28:2537-2539.

Pritchard, J. K., Stephens, M., and Donnelly, P. 2000. Inference of population structure using multilocus genotype data. Genetics 155:945-959.

R Core Team. 2016. R: A Language and Environment for Statistical Computing. R Foundation for Statistical Computing, Vienna, Austria.

Schardl, C. L., Young, C. A., Hesse, U., Amyotte, S. G., Andreeva, K., Calie, P. J., Fleetwood, D. J., Haws, D. C., Moore, N., Oeser, B., Panaccione, D. G., Schweri, K. K., Voisey, C. R., Farman, M. L., Jaromczyk, J. W., Roe, B. A., O'Sullivan, D. M., Scott, B., Tudzynski, P., An, Z., Arnaoudova, 
E. G., Bullock, C. T., Charlton, N. D., Chen, L., Cox, M., Dinkins, R. D., Florea, S., Glenn, A. E., Gordon, A., Guldener, U., Harris, D. R., Hollin, W., Jaromczyk, J., Johnson, R. D., Khan, A. K., Leistner, E., Leuchtmann, A., Li, C., Liu, J., Liu, J., Liu, M., Mace, W., Machado, C., Nagabhyru, P., Pan, J., Schmid, J., Sugawara, K., Steiner, U., Takach, J. E., Tanaka, E., Webb, J. S., Wilson, E. V., Wiseman, J. L., Yoshida, R., and Zeng, Z. 2013. Plantsymbiotic fungi as chemical engineers: Multi-genome analysis of the Clavicipitaceae reveals dynamics of alkaloid loci. PLoS Genet. 9:e1003323.

Schuelke, M. 2000. An economic method for the fluorescent labeling of PCR fragments. Nat. Biotechnol. 18:233-234.

Scott, J. C., Kaur, N., Alderman, S. C., Walenta, D. L., Hamm, P. B., Frost, K. E., and Dung, J. K. S. 2015. Molecular differentiation of Claviceps isolates from Kentucky bluegrass and perennial ryegrass in Oregon and Washington. Phytopathology 105:S4.124-125.

Scott, J. C., Klopp, T., and Dung, J. K. S. 2017. Molecular confirmation of homothallism in Claviceps purpurea. Phytopathology 107:S5.191-192.
Stucky, B. J. 2012. SeqTrace: A graphical tool for rapidly processing DNA sequencing chromatograms. J. Biomol. Tech. 23:90-93.

Tooley, P. W., O’Neill, N. R., Goley, E. D., and Carras, M. M. 2000. Assessment of diversity in Claviceps africana and other Claviceps species by RAM and AFLP analyses. Phytopathology 90:1126-1130.

United States Department of Agriculture-National Agricultural Statistics Service. 2017. Census of Agriculture-State Data. U.S. Department of Agriculture, National Agricultural Statistics Service. https://www.nass.usda. gov/Publications/AgCensus/2017/Full_Report/Volume_1,_Chapter_2_US_ State_Level/st99_2_0026_0026.pdf

White, T. J., Bruns, T., Lee, S., and Taylor, J. W. 1990. Amplification and direct sequencing of fungal ribosomal RNA genes for phylogenetics. Pages 315-322 in: PCR Protocols: A Guide to Methods and Applications. Academic Press, New York.

Winton, L. M., Krohn, A. L., and Leiner, R. H. 2006. Genetic diversity of Sclerotinia species from Alaskan vegetable crops. Can. J. Plant Pathol. 28:426-434. 